\title{
INCLUSÃO EM EDUCAÇÃO: MÚLTIPLOS OLHARES E A CONSTRUÇÃO DE INTERAÇÕES
}

\section{INCLUSION IN EDUCATION: MULTIPLE VIEWS AND THE CONSTRUCTION OF \\ INTERACTIONS}

\author{
Jonathan Aguiar ${ }^{106}$ \\ Alexandra Sudário Galvão Queiroz ${ }^{107}$
}

\begin{abstract}
Resumo
Neste ensaio, buscaremos apresentar o que o Laboratório de Pesquisa e Estudos e Apoio à Participação e à Diversidade em Educação (LaPEADE) tem defendido por Inclusão em Educação, para além do público-alvo da Educação Especial, a partir de suas produções científicas. Busca-se incorporar ao debate, por entender que a bidocência também é um caminho para construção de um ambiente mais inclusivo a sua finalidade. Para tanto, nos aproximaremos dos estudos desenvolvidos por Santos $(2002,2008,2013)$ na defesa da inclusão de todos os indivíduos, assumindo um olhar omnilético (SANTOS, 2013, 2019).
\end{abstract}

Palavras-chave: Inclusão em Educação. Bidocência. Omnilética.

\begin{abstract}
In this essay, we will try to present what the Laboratory for Research and Studies and Support for Participation and Diversity in Education (LaPEADE) has advocated for Inclusion in Education, in addition to the target audience of Special Education, from its scientific productions. It seeks to incorporate into the debate, as it understands that bidocence is also a way to build a more inclusive environment for its purpose. Therefore, we will approach the studies developed by Santos $(2002,2008,2013)$ in defense of the inclusion of all individuals, assuming an omniletic look (SANTOS, 2013, 2019).
\end{abstract}

Keywords: Inclusion in Education. Bidocence. Omnilética.

\footnotetext{
106 Doutorando e mestre em Educação pela Universidade Federal do Rio de Janeiro (UFRJ), sendo bolsista pela CAPES. Pedagogo pela Faculdade de Educação da UFRJ e psicopedagogo (FESL/SP). Pesquisador científico do Laboratório de Pesquisa, Estudos e Apoio à Participação e à Diversidade em Educação (LaPEADE/UFRJ) e membro do Observatório Internacional de Inclusão, Interculturalidade e Inovação Pedagógica (OIIIIPE), sob a coordenação da Profa. Dra. Mônica Pereira dos Santos. E-mail: escritorjonathan@gmail.com. ORCID: https://orcid.org/0000-0001-8517-148X

107 Pós-graduada em Educação Infantil e pedagoga pela Universidade Federal de Mato Grosso (UFMT). Integra o Laboratório de Pesquisa, Estudos e Apoio à Participação e à Diversidade em Educação (LaPEADE/UFRJ) e compõe a equipe do Observatório Internacional de Inclusão, Interculturalidade e Inovação Pedagógica (OIIIIPE). Atua como professora substituta no Colégio de Aplicação da UFRJ. E-mail: profalexandraqueiroz@gmail.com. ORCID: https://orcid.org/0000-0002-9666-2994
} 


\title{
INTRODUÇÃO: UM OLHAR, MÚLTIPLOS OLHARES
}

\begin{abstract}
Uma teoria completa do olhar (sua origem, sua atividade, seus limites, sua dialética) poderá coincidir como uma teoria do conhecimento e com uma teoria da expressão [...]. O olhar não está isolado [...]. Olhar não é apenas dirigir os olhos para perceber o "real" fora de nós. É, tantas vezes, sinônimo de cuidar, zelar, guardar, ações que trazem o outro para a esfera dos cuidados do sujeito: olhar por uma criança, olhar por um trabalho, olhar por um projeto [...].
\end{abstract}

Alfredo Bosi, 2000.

Iniciar este texto com a epígrafe de Alfredo Bosi (2000) acerca do olhar e a sua magnitude nos permite elencar algumas reflexões sobre Inclusão em Educação. A indagação que nos move a respeito da vida humana é: qual é o olhar que possuímos ou construímos quando falamos de inclusão nos espaços escolar e universitário? Seria a bidocência uma maneira de tornar a sala de aula da Educação Básica e do Ensino Superior mais inclusiva? Outra questão que nos move sobre o assunto bidocência é compreender o seu papel no espaço escolar. Afinal, são caminhos, descaminhos, tensões ou possibilidades?

De qualquer modo, inúmeros questionamentos surgem quando a temática é inclusão. É notável que boa parte das pesquisas científicas e eventos acadêmicos, quando tratam desse tema, a maioria das propostas tem como foco o campo da Educação Especial. Salientamos que tal ênfase é legítima e relevante para a área da Educação, mas é essencial ressaltar que pensar e desenvolver pesquisas sobre inclusão é também integrar nesse debate uma dimensão ampla e complexa, para além de um único saber.

Portanto, trabalhar com inclusão, investir em inclusão, ter um olhar mais inclusivo, ser um(a) profissional dedicado em defesa de uma educação para todos, significa compreender que incluir é um processo diário, contínuo e que não possui um fim em si mesmo. O que queremos dizer é que esse ato, ação ou movimento de práticas e aspectos inclusivos não se encerra na área da Educação Especial, ou até mesmo em uma única modalidade de ensino segundo as políticas públicas do nosso país. Apesar desse aspecto, vincular/relacionar a inclusão à Educação Especial pode até ser um início para impulsionar outras problematizações, mas sua proporção é mais ampla do que focar somente nas Pessoas com Deficiência (PCD). 


\section{RevistAleph}

Por esse motivo, buscamos neste ensaio, apresentar o que o LaPEADE, que é coordenado e fundado pela Profa. Dra. Mônica Pereira dos Santos, tem defendido por inclusão em Educação a partir de suas produções científicas (ALVES, 2007; CHAISE, 2007; SILVA, 2008; FONSECA, 2009; BRAZIL, 2010; FREITAS, 2010; MELO, 2010; SANTIAGO, 2011; LEME, 2011; GUEDES L., 2011; GUEDES M., 2011; SILVA, 2012; ARAUJO, 2013; BRITO, 2013; SARDINHA, 2013; MORAIS, 2013; FILGUEIRAS, 2014; LAGO, 2014; COSTA, 2015; MOTTA, 2015; RODRIGUES, 2015; CARNEIRO, 2017; NASCIMENTO, 2017; SANTOS, 2017; SENNA, 2017; PINTO, 2018; LIMA, 2019; OLIVEIRA, 2019; ALMEIDA, 2020; WEBERING; 2020) e, assim, trazer para este debate qual é o papel da bidocência na Educação Básica e no Ensino Superior. Com base nessa ideia, teceremos a seguir alguns olhares: o primeiro, sobre o que defendemos como sendo Inclusão em Educação; o segundo, a respeito da bidocência no sistema educacional, apresentando possíveis caminhos, tensões e aprendizagens; e o terceiro será uma possível conclusão.

\section{INCLUSÃO EM EDUCAÇÃO}

O termo inclusão traz em sua concepção histórica múltiplos significados que divergem entre si, mas, às vezes, também dialogam. Realmente, a busca por um consenso na literatura a respeito do tema não tem sido fácil, principalmente quando o foco é a educação. Mudanças significativas aconteceram após a publicação da Política Nacional de Educação Especial na Perspectiva da Educação Inclusiva (BRASIL, 2008), mas ainda não são suficientes.

A defesa que surge é de uma educação que promova o "direito de todos [...] de estarem juntos, aprendendo e participando sem nenhum tipo de discriminação" (BRASIL, 2008, p. 1). Uma das estratégias citadas nessa política acima é que as "classes especiais" devem ser repensadas em seu modo estrutural e cultural, acarretando o fechamento de "classes especiais" para que, aos poucos, as escolas regulares possam receber esses estudantes em seu cotidiano. Desse jeito, todos vão se inserindo nas escolas regulares e os(as) professores(as) vão atendendo as especificidades de cada indivíduo (BRASIL, 2008).

Evidentemente, a partir desse documento supracitado, boa parte das escolas brasileiras e secretarias municipais de educação começou a ampliar o direito à educação para 


\section{RevistAleph}

uma minoria que não estava frequentando as salas de aulas regulares, de um grupo de estudantes que vivia em lugares isolados, restritos, à margem da sociedade.

Passaram-se 12 anos desde a publicação da Política Nacional da Educação Especial na Perspectiva da Educação Inclusiva (BRASIL, 2008), mas, ainda nos dias atuais, reconhecemos a existência de hiato entre as políticas e os nossas fazeres diários quando é a existência de uma educação que tem como base a inclusão para todos. Tanto que nos espaços de formação inicial e continuada de professores persistimos alertando que educar, ensinar e participar da escola e da sociedade, de modo geral, é um direito de todos.

É preciso destacar que quando falamos em direito de todos, nossos olhares vão ao encontro das pessoas com deficiência, transtornos globais do desenvolvimento e altas habilidades ou superdotação (BRASIL, 1996; 2008; 2015). Então, para além do público alvo da Educação Especial descrito no início desse parágrafo, afirmamos que o direito a educação, deve ser garantido sem restrição de origem, raça, cor, idade ou quaisquer outras formas.

Nessa linha de entendimento, a Organização das Nações Unidas (ONU) lançou no final de 2018 o primeiro relatório - "Realization of the Sustainab le development Goals by, for and with Persons with disabilities" - sobre deficiências e desenvolvimento. Esse relatório destacou lacunas na inclusão das pessoas com deficiência, principalmente na viabilização de uma sociedade mais acessível e inclusiva. Tal relatório salientou que as pessoas com deficiência são mais propensas a viver na pobreza do que as pessoas sem deficiência, e isso devido às barreiras encontradas na sociedade civil. Em consequência disso, surgem a discriminação, 0 acesso limitado à educação e ao emprego, e a falta de meios de subsistência e outros programas sociais (ONU, 2018).

Esse relatório ressalta que, dependendo do país, a discriminação de gênero ou as barreiras enfrentadas por pessoas com deficiência podem ser maiores. Brasil, Costa Rica, República Dominicana e Uruguai são exemplos de países citados onde as mulheres com deficiência conseguem ser mais alfabetizadas, do que os homens (ONU, 2018). Nesse sentido, é válido questionar: como fortalecer um sistema público de educação que promova e garanta processos educativos mais inclusivos para todos, principalmente quando os dados mundiais apontam que essa escola é, em alguns casos, restrita a único gênero?

Dito isso, apresentaremos a seguir o que defendemos por Inclusão em Educação. Como já mencionamos nas linhas iniciais deste ensaio, aqui repetimos que inclusão não se 
resume às Pessoas com Deficiência, mas pretendemos, a partir daqui, nos aproximarmos dos estudos realizados no Laboratório de Pesquisa e Estudos e Apoio à Participação e à Diversidade em Educação (ALVES, 2007; CHAISE, 2007; SILVA, 2008; FONSECA, 2009; BRAZIL, 2010; FREITAS, 2010; MELO, 2010; SANTIAGO, 2011; LEME, 2011; GUEDES L., 2011; GUEDES M., 2011; SILVA, 2012; ARAUJO, 2013; BRITO, 2013; SARDINHA, 2013; MORAIS, 2013; FILGUEIRAS, 2014; LAGO, 2014; COSTA, 2015; MOTTA, 2015; RODRIGUES, 2015; CARNEIRO, 2017; NASCIMENTO, 2017; SANTOS, 2017; SENNA, 2017; PINTO, 2018; LIMA, 2019; OLIVEIRA, 2019; ALMEIDA, 2020; WEBERING; 2020). Tais estudos compreendem a inclusão como um processo de quaisquer lutas, nas diferentes esferas de nossa sociedade, além de atos educativos. Dessa forma, Santos (2013) defende:

A inclusão é considerada como um processo, um aporte teórico e prático a partir do qual uma série de relações precisam ser ressignificadas para que se chegue a um objetivo maior: um mundo justo, democrático, onde as relações sejam igualitárias (ou, pelo menos, menos desiguais) e os direitos, garantidos (SANTOS, 2013, p. 3).

Inclusão, ainda segundo Santos (2003):

[...] não é a proposta de um estado ao qual se quer chegar. Também não se resume à simples inserção de pessoas deficientes no mundo do qual têm sido geralmente privadas. Inclusão é um processo que reitera princípios democráticos de participação social plena. Neste sentido, a inclusão não se resume a uma ou algumas áreas da vida humana, como, por exemplo, saúde, lazer ou educação. Ela é uma luta, um movimento que tem por essência estar presente em todas as áreas da vida humana, inclusive a educacional. Inclusão refere-se, portanto, a todos os esforços no sentido de garantia da participação máxima de qualquer cidadão em qualquer arena da sociedade em que viva, à qual ele tem direito, e sobre a qual ele tem deveres (SANTOS, 2003, p. 81).

De acordo com a ideia exposta acima pela pesquisadora em Educação, a inclusão, num sentido de participação, interação e envolvimento entre indivíduos e sociedade, redimensiona fazeres políticos, práticos, teóricos, epistemológicos, culturais e sociais. Em síntese, incluir implica comprometimento e cooperação, logo, participação.

Inclusão exige da espécie humana mudanças de atitude. Pressupõe olhar para o outro e levá-lo cotidianamente frente aos desafios que surgem, criando outras formas e outras maneiras de tornar a vida o centro da aprendizagem.

Inclusão é ressignificar os olhares que temos sobre alguém ou alguma coisa; é valorizar a diversidade, sendo ela o fio condutor para modificar processos educativos que mobilizam 


\section{RevistAleph}

atitudes criadoras, e, assim, impulsionam o viver e o aprender com o outro como elementos indispensáveis. Isso é riquíssimo para uma educação que não exclui o diferente, mas que, por meio da diferença, acolhe, respeita e transforma vidas.

Acreditamos que instituir um espaço, um ambiente, como salas de aula mais inclusivas, é mais do que organizar estruturas, mas ter objetos adaptados a tais deficiências e fazer uso de algumas metodologias específicas. Esses elementos são indispensáveis no sentido de tornar a escola e as instituições mais acessíveis. No entanto, o que queremos trazer para essa reflexão ultrapassa a objetividade, cujo foco se configura nas sensações, nos sentimentos, nos desejos de cada indivíduo.

Chegamos então no olhar do(a) educador(a), do(a) professor(a), do sujeito, que não deve ser um mero reprodutor(a) ou observador(a), mas deve partir para uma prática mais inclusiva. Ou seja, um profissional que compreende que Inclusão em Educação perpassa as suas ações, pois incluir é um movimento de todos, que mobiliza sentimentos internos e atitudes externas. Incluir é algo plural e subjetivo.

Retomando as produções do LaPEADE, identificamos que as mesmas têm como construto teórico os escritos de Santos $(2003,2013,2015,2019)$, que se relacionam com as abordagens de Booth e Ainscow (2011), tendo em vista três dimensões acerca da Inclusão em Educação, que são estas: a construção de culturas; o desenvolvimento de políticas; e a orquestração de práticas de Inclusão em Educação. Nas palavras de Lima (2019):

\footnotetext{
Booth e Ainscow apresentaram-nos a inclusão como um conceito que busca eliminar barreiras à aprendizagem e à participação, não tendo mais como foco o público alvo da educação especial, mas trazendo uma ideia que passa por deslocar o olhar sobre o sujeito para o contexto no qual este sujeito está inserido (LIMA, 2019, p. 35).
}

Foi a partir desse olhar sobre o sujeito e sobre a relação com as políticas, culturas e práticas, em diálogo com as ideias de Booth e Ainscow (2011), que a pesquisadora Mônica Pereira dos Santos atribuiu a essas dimensões duas outras: a dialética e a complexidade. Em 2013 surge o conceito da Omnilética, que para Santos (2013) é "um modo de explicar/conceber e ser ao mesmo tempo" (p. 23).

Para Pinto (2018), a Omnilética:

[...] é uma forma de compreender o mundo numa tentativa de contemplar

a abrangência dos aspectos contrários, contraditórios e complexos das 
relações, sempre provisórias, que se estabelecem entre as pessoas, no mundo, de uma forma geral (p. 71).

A respeito da terminologia atribuída a Omnilética, Santos (2015) explica:

O prefixo latino omni, que significa tudo, todo, e pode ser acrescentado a praticamente qualquer adjetivo. $O$ radical leto é adotado de sua origem grega, que tem dois sentidos: em seu caráter substantivo (que é o principal sentido utilizado em omnilética), significando o conjunto de elementos (linguísticos) que identifica um grupo no interior de uma comunidade de fala, assumindo, assim, o sentido de variedade. E como verbo, e o que é aqui adotado, que significa 'estar oculto', 'fazer esquecer'. Ao utilizá-lo na omnilética, incorporo este sentido ao conceito de complexidade, que me permite interpretar o que está oculto ou esquecido como algo presente, potencialmente. Por fim, o sufixo ico, também de origem grega, cuja função é formar adjetivos e substantivos eruditos com sentido de 'pertinência', 'relação', 'referência'; 'participação', significando, no neologismo aqui criado, 'relacionado a', ou 'que contém' (SANTOS, 2015, p. 52).

Nesse caso, é correto afirmar que a Omnilética têm cinco dimensões como princípios estruturantes e indissociáveis. São estas: culturas, políticas, práticas, dialéticas e complexidades.

Uma perspectiva omnilética de análise significa, então, em última instância, compreender os fenômenos sociais em sua integralidade visível e em sua potencialidade (ainda invisível, mas não necessariamente ausente, seja por estar apenas oculta, seja por existir, ainda, apenas potencialmente). Significa entender essa integralidade em seus elementos únicos e íntima e dialeticamente relacionados (cultural, política e praticamente) em um movimento de complexidade e espiralar, criando novos patamares de percepção e compreensão dos fenômenos, que nunca mais serão os mesmos, embora mantenham em si um tanto de seus elementos originais, ainda que complexificados (SANTOS, 2013, p. 25).

Para nos aproximarmos dessa perspectiva denominada como Omnilética, múltiplos olhares ressurgem na defesa de uma educação mais participativa, que pode acontecer na Educação Infantil, nos ensinos Fundamental e Médio e, igualmente, no Ensino Superior. A partir desses processos de escolarização, nos deparamos com indivíduos possuidores de conhecimentos sobre a vida, até aqueles que se encontram na fase da infância, que com a descoberta e a curiosidade, contribuem para a construção de um espaço mais inclusivo.

Dentro dessa perspectiva aqui exposta (Omnilética), levantamos a ideia segundo a qual nossos olhares buscam pela Inclusão em Educação ou pela existência de uma educação (c) (1) (2) 


\section{RevistAleph}

que tenha como destaque a defesa da participação de todos os seres humanos. Ou seja, é minimamente saber (e reconhecer) a luta política, filosófica, as práticas sociais que colaboram (ou não) para aquilo que nos impulsionam a professar uma educação para todos. Repetimos: para todos!

O olhar omnilético significa enxergar a complexidade do que seja educar, ensinar diante da pluralidade, da diferença e da diversidade com as quais nos deparamos dentro das instituições de ensino, onde existem crianças e adultos inseridos em esferas que buscam formar profissionais para o mercado de trabalho. As culturas entram nesse jogo; as políticas e práticas ajudam a nortear as experiências. Mas, esse olhar omnilético é amplo, prático, teórico, cultural, político, filosófico e entre outros modos de ser, estar que podem aparecer de modo simultâneo, como também independente. Às vezes é o agir que abre as portas para uma educação que prioriza a inclusão de: indivíduos com deficiência; humanos excluídos por pertencerem a camadas sociais vulneráveis; sujeitos que são marcados pela sua cor, raça, etnia, opção sexual e religião. $O$ docente, educador ou estudante que percebe alguma atitude diante dessas questões logo se posiciona para incluir esses sujeitos. É mais que juntar indivíduos em um único espaço, mas garantir que uns aprendam com os outros.

Vale ressaltar que o olhar omnilético enxerga as sutilezas da vida, os embaraços, e analisa as letras frias de um documento, percebendo suas lacunas e o que pode ser melhorado. Diante de tanta complexidade exposta, esse olhar omnilético é um convite para romper com os rótulos do tipo "este aprende", "este não aprende". É uma forma de nos reeducarmos, de entender que a defesa de uma proposta mais dinâmica e de uma sala de aula mais inclusiva começa também por nós professores quando nos colocamos no lugar de aprendentes e ensinantes, sabendo que incluir diz respeito aos nossos processos de adaptação, modificação de discursos e práticas.

Será a bidocência uma forma de (res)significar a sala de aula, tornando-a mais acessível para quaisquer indivíduos, independente de suas limitações físicas, cognitivas e entre outras? Ou até mesmo a ruptura com documentos/pesquisas que assim explicitam que a inclusão ainda não acontece?

\section{BIDOCÊNCIA: CAMINHOS, TENSÕES OU APRENDIZAGENS?}




\section{RevistAleph}

Nossas escolas vêm passando por diversas transformações no sentido de torna-las acessíveis a todos os seres humanos. Os documentos e as legislações a respeito da educação assumem esse caráter de possibilitar, de construir uma educação ao alcance de todos. Hoje, uma criança a partir dos seus quatro anos de idade tem que estar matriculada na Educação Infantil. Os estabelecimentos de ensino vêm se modificado conforme as determinações, decretos e leis que tornam o espaço educativo acessível, nesse caso a escola universal, tanto para aqueles que moram nas favelas como para aqueles que são ribeirinhos. A escola pode ser para o rico e também para a pessoa com deficiência.

Diante desse cenário, temos presenciado, há aproximadamente uns seis anos, que as instituições públicas têm investido com mais frequência em uma docência compartilhada, ou seja, onde antes habitava um único professor, principalmente nas salas de aulas dos anos iniciais do Ensino Fundamental, passou a ter dois professores (AGUIAR; MAIA, 2018a e 2018b; QUEIROZ, 2019). Mas, o que é isso?

Isso significa o surgimento de um novo profissional, ou seja, um/uma bidocente. Segundo os estudos já desenvolvidos por Capellini (2004), Zanata (2004), Beyer (2005), Toledo (2011), Rabelo (2012), Vilaronga (2014), Zerbato (2014), Martinelli (2016), Mendes (2016), Bueno (2018), Christo e Mendes (2019), a bidocência é um ensino colaborativo, uma docência compartilhada ou qualquer trabalho de apoio entre docentes que tem como foco tornar o espaço escolar mais inclusivo.

É algo que promove aprendizagens significativas para todos, especificamente ao inserirem professores(as) especialistas (da área da Educação Especial) no atendimento aos estudantes com deficiência, ou seja, são profissionais envolvidos com essas dificuldades ou problemas na aprendizagem. Por isso a bidocência se faz necessária, para assim construir a Inclusão em Educação, propiciando uma cultura escolar mais inclusiva em seus aspectos políticos e práticos. Corroborando essa afirmação, podemos perceber tal acepção nas pesquisas de Aguiar e Maia (2018a, 2018b) sobre o (a) professor (a) bidocente. Ao encontro dessas proposições, concordamos com Beyer (2005, p. 11) quando afirma que:

Toda classe que se propõe inclusiva deve dispor do suporte de um segundo professor, em regra com a formação especializada. Com isso, torna-se possivel uma orientação individual conforme as possibilidades e necessidades de cada criança. O conceito de professor isolado perante a tarefa docente fragmenta-se positivamente diante da possibilidade de compartilhar com outro 
colega as experiências do cotidiano escolar. Embora essa situação possa provocar ansiedade nos professores envolvidos em tal experiência, constitui também uma excelente oportunidade para o aperfeiçoamento profissional e pessoal.

Nesse movimento, os (as) professores (as) são tão responsáveis quanto os estudantes da sala de aula. No entanto, cada um tem sua função, mas não agem de maneira isolada. Um depende do outro.

De acordo Damiani apud com Christo e Mendes (2019, p. 36):

O ensino colaborativo, também nomeado de coensino e bidocência, é, portanto, a colaboração do professor de Educação Especial com o professor da Educação Geral, visando ao trabalho em conjunto, com mútuo apoio, buscando atingir objetivos comuns negociados no coletivo, estabelecendo relações que tendem a não hierarquização, exercitando a liderança compartilhada, a corresponsabilidade pelas ações e a confiança mútua (DAMIANI, 2008).

É importante sublinhar que o profissional que atua como bidocente participa ativamente de todos os planejamentos (é o que esperamos) e decisões voltadas para os processos de ensino e aprendizagem. Mesmo diante da especificidade de sua formação acadêmica (ser Especialista em Educação Especial ou em áreas correlatas), juntamente com o outro docente, ambos são responsáveis pela turma e pelos estudantes com deficiência. Colaboram na íntegra para os processos de troca de conhecimentos, trabalhando na elaboração dos planejamentos pedagógicos, conteúdos a serem ensinados, e estratégias de ensino que melhor se adequem às realidades de cada sujeito que compõe o cotidiano escolar.

Como já foi explicitado em parágrafos anteriores, o(a) bidocente pode estar inserido(a) em uma turma devido ao atendimento de algum estudante que seja público alvo da Educação Especial, mas sua presença visa a possibilidade de uma docência colaborativa, propiciando condições para que o educando(a) alcance o mesmo sucesso escolar que seus colegas, eliminando desse jeito os embates e as barreiras que a escola às vezes colocam.

Ainda sobre o papel do (a) bidocente em seu perfil, é necessário dizer que este é diferente daquele que é contratado para trabalhar como mediador(a), cujas funções são bem próximas, mas divergem. Enquanto os(as) mediadores (as) são responsáveis por atender individualmente os (as) alunos (as) com deficiência, o(a) docente que atua na perspectiva da bidocência trabalha em cooperação, em paralelo, de modo concomitante com outro 
professor(a) que não é especialista, mas está comprometido com o ensino e a aprendizagem de todos os estudantes que compõem a turma (MARTINELLI, 2016).

Guthierrez, Oliveira e Barreiros (2016) assim explicam:

É bem-vindo que a bidocência promovida pelo EC (Ensino Colaborativo) caminhe num sentido em que cada vez mais as ações sejam articuladas de modo que as atribuições iniciais passem a se entrelaçar na construção das aprendizagens, e tal relação amplie as diferentes atuações, dado o envolvimento de ambos os docentes com o conjunto das ações e com cada criança (GUTHIERREZ; OLIVEIRA; BARREIROS, 2016, p. 6-7).

$\mathrm{Na}$ verdade, o profissional que vive a bidocência, segundo as problematizações de Queiroz (2019), deve articular sua ação/intencionalidade pedagógica com outros professores(as), compartilhar seus objetivos (o quê pretende alcançar) a respeito do ensino, isso também inclui seus pares, ou seja, o outro docente que também exerce $o$ ato de ensinar/educar na mesma turma.

Com isso, concluímos que a atuação de ambos profissionais se torna eficiente quando quebra as barreiras dos isolamentos (do "eu sou o (a) professor" (a) para "somos docentes", proporcionando, desse jeito, um olhar de parceria, cuidado e profissionalismo). Isso mostra para os estudantes que os dois professores estão na mesma sintonia, no mesmo propósito de contribuir para a autonomia e participação de todos que estão na sala de aula, principalmente aqueles que possuem alguma deficiência ou dificuldade de aprendizagem.

Nessa perspectiva, a participação de todos os (as) professores (as) envolvidos com a turma colabora para a construção de uma escola e sala de aula mais inclusivas. Diferenças existem, mas é por meio delas que conseguimos tornar a sala de aula mais humana, plural, rompendo o discurso de "vamos combater a diferença". Afinal, que bom que existe uma sala de aula onde ninguém é igual a ninguém, e que por meio da diferença é possível promover uma educação que transforma vidas.

Por outro lado, sobre a bidocência, o trabalho em equipe é fundamental, pois a troca de experiências com os colegas, outros professores, educadores e toda a comunidade escolar, vai possibilitando que a escola e a vivência do cotidiano escolar sejam mais prazerosos. No entanto, Queiroz (2019) destaca:

[...] as relações com os sujeitos aprendentes na bidocência atribuem à prática cultural um caminho promissor a superar os desafios dos 
professores e de seus pares, possibilitando um exercício de cidadania, enquanto objeto de formação docente. A reflexão para esse contexto proporcionará uma ação pedagógica capaz de promover novas experiências como suporte na aprendizagem dos alunos com necessidades especiais e outros grupos de estudantes, criando possibilidades de inclusão em educação, visando não só de ordem cognitiva, mas também de ordem afetiva e emocional no ambiente escolar (QUEIROZ, 2019, p. 4).

Portanto, um dos caminhos favoráveis para o exercício da bidocência é a abertura para a ressignificação dos rótulos que determinaram que este é responsável somente pelo estudante com deficiência, quando na verdade é um docente responsável por toda a turma. Diante disso, outros caminhos aparecem, mas a luta é contínua para tal reconhecimento e novos olhares sob aquele que é bidocente.

Outro caminho direciona-se à cultura escolar, que, por sua vez, aguarda a chegada de um(a) bidocente para construir um currículo flexível, (segundo os interesses dos estudantes com deficiência e suas dificuldades na aprendizagem), ou para que haja alteração nas metodologias, posturas e propostas pedagógicas. Reconhecemos que esse caminho pode ser um desafio composto por tensões: até quando a criança, o jovem, o adulto, podem esperar a chegada de um bidocente para que as mudanças ocorram nos estabelecimentos de ensino?

Se defendemos uma educação para todos, com princípios participativos, as mudanças na ótica estrutural devem ocorrer independentemente de haver ou não um bidocente. Nesse aspecto, surge uma tensão, que deve ser discutida em todas as esferas, tanto na Educação Básica como no Ensino Superior.

Ampliando um pouco mais o debate sobre as tensões, segundo os estudos de Aguiar e Maia (2018a, 2018b), podem surgir, entre professores que são responsáveis pela mesma turma, competições, posturas epistemológicas e metodológicas que não dialogam, práticas pedagógicas distintas, conflitos. Mas, podem também aparecer o oposto dessas ações. Mesmo com diferenças, os professores podem se abrir a outros olhares que buscam superar as barreiras relacionais e concretizar um trabalho em equipe. Isso permite uma prática que tem como base a segurança, confiança, empatia e companheirismo, que, por sua vez, tem como objetivo uma educação interativa, participativa e mais inclusiva.

Entre esses caminhos, tensões e aprendizagens, a prática e a ação de um(a) bidocente se resumem a uma construção diária, que acontece no chão da escola, dentro das salas de aula, com o olhar cuidadoso, paciente e investido de profissionalismo e ética. Para além de 


\section{RevistAleph}

mediar o aprendizado do estudante, discutir as necessidades, dificuldades e potencialidades de cada indivíduo - que vivencia a Educação Infantil, Ensino Fundamental, Médio e Superior , é preciso consolidar uma prática pedagógica que tem como finalidade a interação entre sujeitos, independentemente de suas dificuldades.

Cabe ao bidocente implementar em seu contexto escolar ou universitário, planos, metas e estratégias que apresentem alguns direcionamentos futuros, buscando saber aonde quer chegar e o quê deseja alcançar. A adaptação de materiais é importantíssima, tanto para aquele que é público-alvo da Educação Especial como para aquele que não é atendido por essa modalidade, tornando a aprendizagem mais significativa, lúdica, criativa. Com isso, todos aprendem, e não somente aqueles que possuem alguma lacuna na aprendizagem, pois o propósito é ampliar as oportunidades.

\section{CONCLUSÃO: ALGUNS OLHARES}

Ao longo deste trabalho, buscamos trazer, a partir das produções do LaPEADE, um olhar sobre a Inclusão em Educação, ou seja, um outro olhar partir das lentes da omnilética. Com isso, chegamos à conclusão que a Inclusão em Educação é um processo contínuo, diário, amplo, múltiplo. Seu foco é a vida humana, de modo a propiciar a participação plena de qualquer indivíduo no processo de ensino-aprendizagem.

A respeito da participação e interação em vários setores da sociedade, de modo específico na Educação, alguns estabelecimentos de ensino e outros profissionais podem elencar que uma maneira de tornar o espaço educacional mais inclusivo é quando este possui profissionais que são bidocentes. Desse jeito, entramos nesse aspecto e questionamos: é um caminho, descaminho, tensão ou possibilidade? Concluímos que quando olhamos omniléticamente para a atuação, o perfil e como o(a) bidocente se insere no espaço escolar, universitário e suas implicações, percebemos que o direto à aprendizagem deve acontecer independentemente de existir ou não um profissional especialista.

Por outro lado, a inclusão remete ao esforço de todos. Que comecemos, pois, dentro de nossas salas de aulas, a refletir sobre o trabalho da bidocência, enxergando o quanto a atuação deste profissional está investida de parceria, acolhimento e troca de saberes entre 


\section{RevistAleph}

seus pares. Talvez esteja aí uma forma de mostrar outras maneiras de ser docente, ser colaborativo e solidário.

Este estudo deixa visível a necessidade de mais pesquisas sobre o campo da bidocência e sua interface com os processos de ensino-aprendizagem, sobretudo seus respectivos desdobramentos nos cotidianos de nossos estudantes. Até porque o Ensino Colaborativo ainda precisa de outros enfoques, olhares, práticas, epistemologias e novos caminhos que tem como defesa uma educação mais inclusiva ao alcance de todos, ao alcance da espécie humana. Outro olhar viável é a perspectiva omnilética por quebrar as certezas, as lógicas e assim entender as múltiplas facetas com a inserção de um(a) bidocente.

\section{Referências}

AGUIAR, Jonathan Fernandes de; MAIA, Maria Vitória Campos Mamede. Percepções de uma professora que atua como bidocente: em defesa de uma educação inclusiva. Pesquisa e Prática em Educação Inclusiva, v. 1 n. 2 , 2018a. Disponível em: https://periodicos.ufam.edu.br/index.php/educacaolnclusiva/article/view/4689/4167

AGUIAR, Jonathan; MAIA, Maria Vitória Campos Mamede. "O grande desafio é educar para a diversidade": inclusão aos olhos de uma bidocente. Anais do 8 Congresso Brasileiro de Educação Especial, 2018b, São Carlos. Anais eletrônicos... Campinas, Galoá. Disponível em: https://proceedings.science/cbee/cbee-2018/papers/----o-grande-desafio-e-educar-para-adiversidade-----inclusao-aos-olhos-de-uma-bidocente

ALMEIDA, Maicon Salvino Nunes de. Reflexões Omniléticas sobre o Acesso e a Permanência de Crianças Refugiadas Congolesas no Rio de Janeiro. Dissertação (Mestrado em Educação) Faculdade de Educação da Universidade Federal do Rio de Janeiro, Rio de Janeiro, 2020.

ALVES, Cristina Nacif. O Sentido dos Argumentos para a Formação de Coordenadores Pedagógicos: caminhos para a aproximação entre teoria e prática. Dissertação (Mestrado em Educação). Universidade Federal do Rio de Janeiro, Faculdade de Educação, Rio de Janeiro, 2007.

ARAUJO, Giselle de Oliveira. As Políticas Universitárias e sua Influência na Concepção de Docentes sobre inclusão/exclusão: Percepções de Brasil e Portugal nos cursos de Formação de Professores Rio de Janeiro, 2013. Dissertação (Mestrado em Educação). Faculdade de Educação, Universidade Federal do Rio de Janeiro, Rio de Janeiro, 2013.

BEYER, Hugo Otto. O pioneirismo da escola flämming na proposta de integração (inclusão) escolar na Alemanha: aspectos pedagógicos decorrentes. Revista Educação Especial, Santa Maria, p. 09-24, mar. 2005. ISSN 1984-686X. Disponível em:

<https://periodicos.ufsm.br/educacaoespecial/article/view/4900/2937>. Acesso em: 10 abr. 2020.

BOOTH, Tony; AINSCOW, Mel. Index para Inclusão: Desenvolvendo a Aprendizagem e a Participação na Escola. 3. ed. UNESCO/CSIE. Rio de Janeiro, 2011. Tradução de Mônica Pereira dos Santos. 


\section{RevistAleph}

Disponível em: $<$ http://www.lapeade.com.br/publicacoes/documentos/index2012final\%20FOTOS\%20BRASIL.pdf>. Acesso em 25 de mar. de 2020.

BOSI, Alfredo. Fenomenologia do olhar. In: NOVAES, Adauto (Org.) O olhar. São Paulo: Companhia das Letras, 1988. p. 65-87.

BRASIL. Lei Brasileira da Inclusão. LEI № 13.146, DE 6 DE JULHO DE 2015. Disponível em: L13146. Acesso em 25 de mar. de 2020.

BRASIL. Lei Diretrizes e Bases da Educação. LEI № 9.394, DE 20 DE DEZEMBRO DE 1996. Disponível em: http://www.planalto.gov.br/ccivil_03/Leis/L9394.htm. Acesso em 25 de mar. de 2020.

BRASIL. Política Nacional da Educação Especial na Perspectiva da Educação Inclusiva. MEC/SECADI, 2008. Disponível em:

http://portal.mec.gov.br/index.php?option=com_docman\&view=download\&alias=16690-politicanacional-de-educacao-especial-na-perspectiva-da-educacao-inclusiva-05122014\&ltemid=30192. Acesso em 25 de mar. de 2020.

BRAZIL, Christina Holmes. O Programa Nacional Escola de Gestores em Foco: Um Estudo de Caso sobre Culturas, Políticas e Práticas de Inclusão em Educação. Rio de Janeiro, 2010. Dissertação (Mestrado em Educação). Faculdade de Educação Universidade Federal do Rio de Janeiro. Rio de Janeiro, 2010.

BRITO, Leandro Teofilo de. Inclusão em Educação, gênero e sexualidade: um estudo de caso. Rio de Janeiro, 2013. Dissertação (Mestrado em Educação). Faculdade de Educação, Universidade Federal do Rio de Janeiro, Rio de Janeiro, 2013.

BUENO, Melina Brandt. Educação de Jovens e Adultos: formação continuada colaborativa entre professores da sala comum e da educação especial. Dissertação (mestrado)-Universidade Federal de São Carlos, campus São Carlos, São Carlos, 2018.

CAPELLINI, Vera Lúcia Messias Fialho. Avaliação das Possibilidades do Ensino Colaborativo no Processo de Inclusão Escolar do Aluno com Deficiência mental. São Carlos, UFSCar, 2005,300p. Tese (Doutorado), Universidade Federal de São Carlos, 2004.

CARNEIRO, Lillian Auguste Bruns Carneiro. Da universidade como auditório e do professor como orador: uma análise omnilética dos argumentos de valorização, desvalorização da carreira docente. Tese (Doutorado em Educação). Programa de Pós-Graduação em Educação da Universidade Federal do Rio de Janeiro - UFRJ. Rio de Janeiro, 2017.

CHAISE, Rosa Maria. Escolas de Contas e de Gestão: será o conhecimento um fator para a concretização da cidadania fortalecendo a Esfera Pública? Tese (Doutorado em Educação) Faculdade de Educação, Universidade Federal do Rio de Janeiro, Rio de Janeiro, 2007.

CHRISTO, Sandy Varela de; MENDES, Geovana Mendonça Lunardi. Ensino colaborativo/coensino/bidocência para a educação inclusiva: as apostas da produção científica. Instrumento: Rev. Est. e Pesq. em Educação, Juiz de Fora, MG,v. 21, n. 1, p. 33-44, jan./jun. 2019 Ensino colaborativo/coensino/bidocência para a educação inclusiva Instrumento: Revista de Estudo e Pesquisa em Educação. Acessado 30/03/2020. 
COSTA, Erika de Souza. A inclusão do alunado do atendimento educacional especializado no município do Rio de Janeiro. Dissertação (Mestrado em Educação). Faculdade de Educação, Universidade Federal do Rio de Janeiro, Rio de Janeiro, 2015.

FILGUEIRAS, Elisa Maria Maçãs Fernandes de Castro. Reconhecimento social dos educadores do ensino superior a distância: possibilidades, dificuldades e dilemas. Tese (Doutorado em Educação). Faculdade de Educação. Universidade Federal do Rio de Janeiro, 2014.

FONSECA, Michele Pereira de Souza da. Inclusão: Culturas, políticas e práticas de inclusão na formação de professores de Educação Física da UFRJ. Rio de Janeiro, 2009. Dissertação (Mestrado em Educação). Faculdade de Educação, Universidade Federal do Rio de Janeiro, Rio de Janeiro, 2009.

FREITAS, José Guilherme de Oliveira. No quadro: o tema diversidade sexual na escola, com foco na homossexualidade. Nas carteiras escolares: os professores. Rio de Janeiro, 2010. Tese (Doutorado em Educação). Faculdade de Educação, Universidade Federal do Rio de Janeiro, Rio de Janeiro, 2010.

GUEDES, Luísa Azevedo. Das Culturas às Práticas: $\mathbf{O}$ que dizem Professores do Ensino Médio de uma escola pública sobre Processos de Inclusão/Exclusão. Dissertação (Mestrado em Educação). Faculdade de Educação, Universidade Federal do Rio de Janeiro, Rio de Janeiro, 2011.

GUEDES, Marta Cardoso. Inclusão em Educação na Rocinha: Vivências Lúdico-Criadoras do Fazer Artístico nas Culturas, Políticas e Práticas de uma escola de Ensino Fundamental. Rio de Janeiro, 2011. Dissertação (Mestrado em Educação). Faculdade de Educação, Universidade Federal do Rio de Janeiro, Rio de Janeiro, 2011.

GUTHIERREZ, Carla Cordeiro Marçal Y; OLIVEIRA, Crizan; BARREIROS, Claudia. Inclusão, bidocência, ensino colaborativo: quem ganha com isso?. In: ANAIS DO 70 CONGRESSO BRASILEIRO DE Educação ESPECIAL, 2016, São Carlos. Anais eletrônicos... Campinas, Galoá, 2020. Disponível em:

<https://proceedings.science/cbee/cbee7/papers/inclusao--bidocencia--ensino-colaborativo--quemganha-com-isso-> Acesso em: 10 abr. 2020.

LAGO, Mara. Index para a Inclusão: uma possibilidade de intervenção institucional. Tese (Doutorado em Educação). Faculdade de Educação, Universidade Federal do Rio de Janeiro, Rio de Janeiro, RJ, 2014.

LEME, Erika Souza. Inclusão em Educação: Das políticas públicas às práticas do cotidiano escolar. Rio de Janeiro, 2011. Dissertação (Mestrado em Educação). Faculdade de Educação, Universidade Federal do Rio de Janeiro, Rio de Janeiro, 2011.

LIMA, Carolina Barreiros de. "Como você não é da casa, isso não te pertence, esse espaço não é seu..." Ou seria? Sentidos de inclusão em uma Escola de Governo. Dissertação (Mestrado em Educação). Faculdade de Educação da Universidade Federal do Rio de Janeiro, Rio de Janeiro, 2019.

MARTINELLI, Josemaris Aparecida. Trabalho Colaborativo entre uma Professora Especialista e Professores do Ensino Comum para a Inclusão de Alunos com Necessidades Educacionais Especiais. 2016. p. 154. Dissertação (Mestrado em Educação) - Universidade Estadual de Londrina, Londrina, 2016.

MELO, Sandra Cordeiro de. Inclusão em educação: Um estudo sobre as percepções de professores da rede Estadual de Ensino Fundamental do Rio de Janeiro, sobre práticas pedagógicas de inclusão. 
Tese (Doutorado em Educação). Programa de Pós-Graduação em Educação, Universidade Federal do Rio de Janeiro, 2010.

Mendes, Melina Thaís da Silva. Ensino colaborativo na educação infantil para favorecer o desenvolvimento da criança com deficiência intelectual. São Carlos. UFSCar, 2016. Dissertação (Mestrado) -- Universidade Federal de São Carlos, 2016.

MORAIS, Silvilene de Barros Ribeiro. Museu de Ciência: o diálogo com as diferenças. Dissertação (Mestrado em Educação). Faculdade de Educação. Universidade Federal do Rio de Janeiro. Rio de Janeiro, 2013.

MOTTA, Gláucio Rodrigues. Formação de professores para o contexto da educação inclusiva: o Instituto Federal do Espírito Santo e os fatores atuantes sobre seus espaços formativos. 2015. Tese (Doutorado em Educação). Faculdade de Educação, Universidade Federal do Rio de Janeiro, Rio de Janeiro, 2015.

NASCIMENTO, Leyse Monick França. Formação continuada de professores na perspectiva do Index para inclusão: educação especial e educação regular em foco. Rio de Janeiro, 2017. Dissertação (Mestrado em Educação). Faculdade de Educação, Universidade Federal do Rio de Janeiro, Rio de Janeiro, 2017.

ONU. Realization of the Sustainab le development Goals by, for and with Persons with disabilities. Department of Economic and Social Affairs: ONU, 2018. Disponível em: REALIZATION OF THE SUSTAINABLE DEVELOPMENT GOALS BY, FOR AND WITH PERSONS WITH DISABILITIES

OLIVEIRA, Raquel Batalha de. Observatório Internacional de Inclusão, Interculturalidade e Inovação Pedagógica: uma análise da participação dos pesquisadores. Dissertação (Mestrado em Educação). Faculdade de Educação da Universidade Federal do Rio de Janeiro, Rio de Janeiro, 2019.

PINTO, Regina Maria de Souza Correia. O desenvolvimento do Index para a Inclusão como estratégia de combate à exclusão: instigando a autoavaliação institucional em uma Escola de Governo. Rio de Janeiro, Tese (Doutorado em Educação). Programa de Pós-Graduação em Educação da Universidade Federal do Rio de Janeiro-UFRJ, 2018.

QUEIROZ, Alexandra sudário Galvão. Práticas Curriculares na Formação de Professores: Um Inventário da Bidocência nos Anos Iniciais. X Seminário Internacional. As Redes Educativas e as Tecnologias Liberdade acadêmica, produção e circulação de conhecimentos. Universidade do Estado do Rio de Janeiro - UERJ -Faculdade de Educação - EDU. 01 a 04 de julho de 2019.

Disponível em: As Redes Educativas e as Tecnologias

RABELO, Lucélia Cardoso Cavalcante. Ensino Colaborativo como Estratégia de Formação Continuada de Professores para Favorecer a Inclusão Escolar. São Carlos, UFCar,2012, $200 f$. Dissertação Mestrado, Universidade Federal de São Carlos, 2012.

RODRIGUES, Michely Aguiar. 0 processo de inclusão da criança com autismo: mapeando práticas escolares e seus efeitos. Rio de Janeiro, 2015. Dissertação (Mestrado em Educação). Faculdade de Educação, Universidade Federal do Rio de Janeiro, Rio de Janeiro, 2015. 
SANTIAGO, Mylene Cristina. Laboratório de Aprendizagem: das políticas às práticas de inclusão e exclusão em educação. 2011. Tese (Doutorado em Educação)-Faculdade de Educação, Universidade Federal do Rio de Janeiro, Rio de Janeiro, RJ, 2011.

SANTOS, Mônica Pereira dos. Dialogando sobre inclusão em educação: contando casos (e descasos). 1. ed. Curitiba, PR: CRV, 2013.

SANTOS, Mônica Pereira dos. Inclusão, Direitos Humanos e Interculturalidade: uma tessitura omnilética. In: CASTRO, P. A. de. (Org.) Inovação, Ciência e Tecnologia: desafios e perspectivas na contemporaneidade [Livro Eletrônico]. Editora Realize: Campina Grande-PB, 2015, p. 49-66. Disponível em:

http://editorarealize.com.br/revistas/ebook_conedu/trabalhos/ebook_conedu.pdf\#page=49

SANTOS, Mônica Pereira dos. O papel do ensino superior na proposta de uma educação inclusiva. Revista da Faculdade de Educação da UFF, n.7, maio, 2003, p.78-91.

SANTOS, Mônica Pereira dos. Inclusion of People with Disabilities in Brazil: Towards an Omnilectical Policy Analysis. European Journal of Educational Management. vol2, Issue 2, p. 45 - 57, 2019. Disponível em:

https://www.researchgate.net/profile/Monica_Santos4/publication/340309968_European_Journal_ of_Educational_Management_Inclusion_of_People_with_Disabilities_in_Brazil_Towards_an_Omnile ctical_Policy_Analysis/links/5e83650592851c2f5270b881/European-Journal-of-EducationalManagement-Inclusion-of-People-with-Disabilities-in-Brazil-Towards-an-Omnilectical-PolicyAnalysis.pdf

SANTOS, Monica. Culturas, Políticas e Práticas de Inclusão na Administração Pública: Contribuições a Partir de Uma Escola de Governo. Rio de Janeiro, 2017. Dissertação (Mestrado em Educação). Faculdade de Educação, Universidade Federal do Rio de Janeiro, Rio de Janeiro, 2017.

SARDINHA, Gabriela da Silva. Impactos da Gestão Escolar no Desenvolvimento de Processos de Inclusão em Uma Escola Pública de Ensino Médio do Rio de Janeiro: um estudo de caso. Rio de Janeiro, 2013. Dissertação (Mestrado em Educação). Faculdade de Educação, Universidade Federal do Rio de Janeiro, Rio de Janeiro, 2013.

SENNA, Manoella. (Re)visiting cultures, policies and practices of inclusion in Education at the municipal management level of education: the second Education Regional Coordination (2a CRE) in action. Dissertation (Master in Education). College of Education, Federal University of Rio de Janeiro, Rio de Janeiro, 2017.

SILVA, Ana Patrícia da. Corpo, inclusão / exclusão e formação de professores. Rio de Janeiro, 2012. Tese (Doutorado em Educação) - Faculdade de Educação, Universidade Federal do Rio de Janeiro, Rio de Janeiro, 2012.

SILVA, Rossicleide Santos da. Possibilidades Formativas da Colaboração entre professores do Ensino Comum e Especial em um município. Paraense, 2018,139 f. Dissertação (Mestrado) Universidade de São Carlos, 2018.

SILVA, Kátia Regina Xavier da. Criatividade e inclusão na formação de professores: Representações e Práticas Sociais. Rio de Janeiro, 2008. Tese (Doutorado em Educação). Faculdade de Educação, Universidade Federal do Rio de Janeiro, Rio de Janeiro, 2008. 


\section{RevistAleph}

TOLEDO, Elizabete Humai de. Formação de professores em serviço por meio de pesquisa colaborativa visando à inclusão de alunos com deficiência intelectual. 2011. 189 f. Dissertação (Mestrado em Educação) - Programa de Pós-Graduação em Educação, Universidade Estadual de Londrina, Londrina, 2011.

VILARONGA, Carla Ariela Rios. Colaboração da educação especial em sala de aula: formação nas práticas pedagógicas do coensino. 2014. 216 f. Tese (Doutorado) - Universidade Federal de São Carlos, São Carlos, 2014.

WEBERING, Fernanda Iglesias. Acessibilidade como um instrumento de inclusão no ensino superior: a UFRJ em um novo cenário. Dissertação (Mestrado em Educação) - Faculdade de Educação da Universidade Federal do Rio de Janeiro, Rio de Janeiro, 2020.

ZANATA, Eliana Marques. Práticas Pedagógicas Inclusivas para Alunos Surdos numa Perspectiva colaborativa. São Carlos, UFCar, p.198. Tese (doutorado) Universidade Federal de São Carlos,2004.

ZERBATO, Ana Paula. O papel do professor de Educação Especial na proposta do coensino. Dissertação de Mestrado em Educação Especial. Universidade Federal de São Carlos. SP: UFSCar, 2014.

Data do envio: $16 / 04 / 2020$

Data do aceite: 03/06/2020. 